\title{
Effect of hollow glass microspheres addition on density reduction and mechanical properties of PA6/glass fibers composites
}

\author{
Thaysa Rodrigues Mendes Ferreira' ${ }^{1}$, Matheus de Alencar Lechtman' ${ }^{1}$ (D), Filipe Lauro Dias $^{2}$ (D) and \\ Aline Bruna da Silva ${ }^{1 *}$ (D) \\ ${ }^{1}$ Laboratório de Polímeros, Departamento de Engenharia de Materiais, Centro Federal de Educação \\ Tecnológica de Minas Gerais - CEFET, Belo Horizonte, MG, Brasil \\ ${ }^{2}$ Engenharia de Materiais, Stellantis, Betim, MG, Brasil \\ *alinebruna@cefetmg.br
}

\begin{abstract}
The strategy of combining the traditional reinforcement of glass fibers (GF) with lighter hollow glass microspheres (HGM) can afford to fulfill the need for potential light-weight and high-strength modern materials required in various sectors, such as automotive and aerospace industry applications. This work fabricated composites of PA6/GF/HGM by melting blending in a co-rotating twin-screw extruder, and subsequently, injection molded. The effects of HGM content on the density, morphological and mechanical properties were investigated and the PA6/GF/HGM composites properties were compared to the properties of the traditional PA6/GF (70/30) wt $\%$ composite, widely used today in automotive industries. With the increase of HGM amount in the formulations, a reduction of between 3 and $12 \%$ in density was achieved with a slight reduction in its mechanical properties, showing that this new strategy can be applied to replace the PA6/GF (70/30) wt\% composite, providing a considerable weight reduction for these materials.
\end{abstract}

Keywords: polyamide composites, glass microspheres, glass fibers, density eduction, weight reduction.

How to cite: Ferreira, T. R. M., Lechtman, M. A., Dias, F. L., \& Silva, A. B. (2022). Effect of hollow glass microspheres addition on density reduction and mechanical properties of PA6/glass fibers composites. Polímeros: Ciência e Tecnologia, 32(1), e2022001. https://doi.org/10.1590/0104-1428.210060

\section{Introduction}

The aerospace and automotive industries are constantly searching for new technologies to improve their performance, especially new materials, to fabricate components lighter, optimize the consumption of fuel, and make the aircraft and vehicles faster and efficient ${ }^{[1]}$. Throughout history, several advances have been achieved, the replacement of metal parts by plastic material can be highlighted as one of the changes that directly impacted the performance of vehicles and aircraft ${ }^{[2]}$. Despite the replacement of metal parts by plastic results in a significant reduction in weight, its mechanical properties are usually lower than required by those applications. To enable the replacement of more metal parts by lighter materials polymer composites reinforced with anisotropic fillers, such as glass fiber (GF), and carbon fiber, and or inorganic filler such as talc and calcium carbonate have been produced to be used for those sectors of the industry ${ }^{[3,4]}$.

Considering the reinforcement characteristics, anisotropic fillers are more efficient compared to isotropic fillers ${ }^{[5,6]}$ due to their high surface area ratio. Fiber-reinforced materials have expanded the use of thermoplastics into structural applications, and in this context, GF has long been the reinforcement of choice, since they meet many structural

and durability demands of the aerospace and automotive industries ${ }^{[7]}$ because of its high specific strength and high specific modulus of elasticity. Glass fiber-reinforced plastics (GFRP) have thus become a commodity material in the automotive, aerospace, and construction industries ${ }^{[8]}$. Although, these fillers may result in the increased density of the final composite. Thus, despite the advance in the development already achieved by the GFRPs, the development of new strategies to obtain the composites materials based on polymer and GF are still needed. The strategy of producing a composite combining the traditional reinforcement of GF with a lighter filler can afford to fulfill the need for potential light-weight and high-strength modern materials required in various sectors, such as automotive and aerospace industry applications ${ }^{[9]}$. This particulate filler can be spheres, blocks, or needle kind. Hollow glass microspheres (HGM), also known as glass bubbles, are an example of sphere inorganic reinforcement applied to obtain lighter composites materials ${ }^{[10,11]}$.

Hollow microspheres, especially glass ones, are used to reduce weight and to impart specific properties to polymeric materials for various applications ${ }^{[12-15]}$. HGM are spherical thin-walled glass $(0.5-2.0 \mu \mathrm{m})$ made of outer stiff glass and 
inner inert gas, with average diameter between 10-200 $\mu \mathrm{m}$, which combine very low weight, high resistance to uniform compression, good thermal properties, acoustic insulation and good dielectric properties ${ }^{[16]}$. The incorporation of HGM to replace the amount of glass fibers face a challenge in the processing of traditional composites, due to the brittle feature of the thin wall glass. Thus, a large amount of HGM fracture during extrusion and injection process, the scientific literature brings as one solution the two-stage processing method, based on twin-screw extrusion ${ }^{[17-20]}$. The twin-screw extrusion processing is commonly used to improve the distribution and dispersion during the mixing process on the extrusion, and the two stages prevent the breakage of the glass fibers and HGM, what ensure a better efficiency process compared with the traditional single screw method.

Nowadays, HGM composites are also an object of study in additive manufacturing, such as $3 \mathrm{D}$ printing, to improve flow melting and thermal insulation ${ }^{[21]}$. Özbay and Serhat ${ }^{122]}$ studied processing and properties of different combinations of HGM filled with polyamide 12 (PA12) matrix, by Selective Laser Sintering (SLS) manufacturing method. As a result, they obtained a $20 \%$ of density reduction and a significant rise in the E-modulus with the composition PA12/HGM (80/20).

In the automotive industry, the polyamide (PA6) and polyamide 6.6 (PA66) are often used because of their typical hydrogen bonds, due to their polar chemical structure ${ }^{[23]}$, with a short GF reinforcement, commonly $30 \mathrm{wt} \%$. Composites of PA6 or PA66 reinforced with glass fibers ensure great mechanical and thermal properties and can be found in air intake manifolds, rocker covers, radiator end tanks, fuel rails, electrical connectors, engine encapsulation and others ${ }^{[2,24]}$. In this sense, GF and HGM combination may constitute an excellent solution to combine lower density, dimensional stability, and good mechanical properties. Berman et al. ${ }^{[25]}$ have studied the effects of replacing calcium carbonate (high density filler) with HGM (low density filler) in an unsaturated polyester resin matrix sheet molding compound (SMC) reinforced with short GF (10 15 wt \%). The composite was fabricated in SMC manufacturing, lay-up and hot pressing. As a result, they obtained a $12 \%$ of density reduction but compromised the mechanical properties. Nevertheless, all values of tensile, flexural and impact properties were higher than the corresponding properties of low and ultra-low-density composites reported in the literature.

Thus, the goal of this study was to fabricate a composite based in PA6 reinforced with GF and HGM and to investigate the effects of HGM content on the density, mechanical properties of the composites comparing its properties with the traditional PA6/GF (70/30) wt $\%$ composite, widely used today in automotive industries. It's expected to find a formulation with at least $10 \%$ density reduction and maintenance of mechanical properties. In this paper, fundamental results for understanding the relationship between structure and property of both the matrix and the fillers will be discussed in terms of microscopic observations, mechanical properties, and thermal stability.

\section{Materials and Methods}

\subsection{Materials}

The injection molding grade polyamide 6 (B30S) with density of $1.14 \mathrm{~g} / \mathrm{cm}^{3}$ was provided by LANXESS. Glass fiber was provided by LANXESS, with medium range length of 3 to $4.5 \mathrm{~mm}$, the density of $2.45 \mathrm{~g} / \mathrm{cm}^{3}$ and chemical compatibilization with an organosilane. Hollow glass microspheres type S42XHS ( $\left.3 \mathrm{M}^{\mathrm{TM}}\right)$ was provided by $3 \mathrm{M}$ with untreated surface, density of $0.42 \mathrm{~g} / \mathrm{cm}^{3}$, nominal crush strength $=8,000 \mathrm{psi}$ and size distribution $=20-29 \mu \mathrm{m}$.

\subsection{Composites preparation}

The PA6/glass fibers composites and PA6/glass fibers/ hollow glass microsphere composites were produced by melting blending using a Thermo Scientific Haake Rheomex PTW 24 OS co-rotating twin-screw extruder, with a side feeder $(\mathrm{L} / \mathrm{D}=35)$. The twin-screw speed and temperature at the die were $200 \mathrm{rpm}$ and $250^{\circ} \mathrm{C}$, respectively. To mixture preparation, the GF and HGM were added in the side feeder, in order to prevent its break. First of all, PA6/GF composites with $30 \mathrm{wt} \%$ of glass fibers were prepared and separated as the reference sample. The processing of the PA6/GF/ HGM composites was performed in two stages to prevent the HGM breakage due to abrasive contact with glass fiber and shear stress during mixing ${ }^{[19,20]}$. In the first stage, only the PA6 and glass fibers were mixed in the extruder and in the second stage, the pellets of the first stage and HGM were mixed. Both fillers were introduced in the side feeder. The twin screw speed and barrel temperature at the die were $200 \mathrm{rpm}, 250^{\circ} \mathrm{C}$ the same used to the reference sample. The total amount of fillers was kept in $30 \mathrm{wt} \%$ for all formulations, changing the HGM content relative to the GF content. Table 1 shows the studied formulations with respective amount of PA6, GF and HGM.

After extrusion, tensile specimens were obtained by injection molding, according to ASTM D638, using a Thermo Scientific equipment. The injection molding conditions comprised: barrel temperature profile $260 / 270 / 282 / 280 / 280^{\circ} \mathrm{C}$, mold temperature $80^{\circ} \mathrm{C}$, injection pressure 700 bar and injection speed $25 \mathrm{~mm} / \mathrm{min}$.

\subsection{Filler characterization}

A calcination experiment was made, based on ISO 3451-1 (method A) to quantitative evaluation of inorganic filler. For this analysis, 3 specimens each formulation were burned using methane gas. After the extinguishment of the flame, only a white residue and black ash were left. They represent the organic load and inorganic filler, respectively. Subsequently, the specimens were placed in a furnace at

Table 1. Samples formulation with PA6, GF and HGM content relative.

\begin{tabular}{cccc}
\hline Sample & PA6 (wt\%) & GF (wt\%) & HGM (wt\%) \\
\hline A & 70.0 & 30.0 & 0.0 \\
B & 70.0 & 27.0 & 3.0 \\
C & 70.0 & 25.0 & 5.0 \\
D & 70.0 & 22.5 & 7.5 \\
E & 70.0 & 20.0 & 10.0 \\
\hline
\end{tabular}


$750^{\circ} \mathrm{C}$ for 30 minutes, to full degradation of the organic load. The amount of inorganic filler in samples was calculated with the Equation 1.

$$
\%_{\text {residue }}=\frac{\left(\text { Mass }_{\text {calcined }}-\text { Mass }_{\text {crucible }}\right)}{\left(\text { Mass }_{\text {sample }}\right)} \times 100
$$

To evaluate the morphology of the filler after processing a Scanning Electron Microscopy (SEM) Shimadzu SSX-550 Superscan model was used on samples A and $\mathrm{C}$ to fibers, and on sample $\mathrm{C}$ to HGM. The average $\mathrm{L} / \mathrm{D}$ of fibers and diameter of HGM after the calcination experiment was measured using the IMAGE Pro-plus 4.5 software. For each sample, 50 examples of GF and HGM was measured.

\subsection{Composites characterization}

To study the PA6/GF and PA6/GF/HGM composites morphology, density and mechanical behavior, the injected specimens were previously placed in an oven for 24 hours at $95^{\circ} \mathrm{C}$. This procedure aims to reduce the humidity of the material, which could affect the results since PA6 is a highly hygroscopic polymer ${ }^{[26}$. Scanning electron microscopy (SEM) observations, using a Shimadzu SSX-550 Superscan model, were carried out over the cross-section of cryofractured surface (made with liquid nitrogen). Specimens of all compositions were evaluated and the distribution and adhesion of the fillers were analyzed.

The samples densities measured were carried out with a Sartorius analytical balance (2006), according to ISO 1183-1 method A, using Archimedes principle. First, an empty beaker was placed above the plate of the balance, and the balance was tarred. Then the weight of 3 specimens of each composition was record. After that, the beaker was filled with $500 \mathrm{ml}$ of water at $23{ }^{\circ} \mathrm{C}$ and the balance was tarred again. Each specimen, suspended with a copper wire, was submerged in water, and the weight was recorded. The density was calculated following Equation 2. Density water was considered $1.0 \mathrm{~g} / \mathrm{cm}^{3}$.

$$
\text { Density }_{\text {sample }}=\left[\frac{\text { Mass }(\text { sample })_{\text {air }} * \text { Density }_{\text {water }}}{\left(\text { Mass }(\text { sample })_{\text {air }}-\text { Mass }(\text { sample })_{\text {submerged }}\right)}\right]
$$

For mechanical characterization, tensile and Izod impact tests were performed. The tensile test was carried out using an Instron universal testing machine, model 4467, according to ISO 527 standard test method (specimen dimension = $80 \times 5 \times 2 \mathrm{~mm}$ ). The strain rate was set to $50 \mathrm{~mm} / \mathrm{s}$, also, an extensometer of $50 \mathrm{~mm}$ and a load cell of $30 \mathrm{kN}$ were used. The Izod impact was carried out in a Ceast equipment $6545 / 000$ model, according to ISO 180 standard test method (specimen dimension $=80 \times 10 \times 4 \mathrm{~mm}$ ), with the pendulum of $2.75 \mathrm{~J}$ and preloading of $0.011 \mathrm{~J}$. All mechanical tests were performed at room temperature, and at least, five test specimens were used for testing each formulation.

\subsection{Efficiency metric}

To compare the performance of the formulations, the percentage of density reduction was divided by the percentage of change in mechanical properties. $\mathrm{E}_{\mathrm{DT}}$ and $\mathrm{E}_{\mathrm{DI}}$ refers to efficiency density reduction by tensile strength test and by impact test, respectively. Equation 3 and Equation 4 shows how it was calculated.

$$
\begin{aligned}
& E_{D T}=\Delta \% \text { density } / \Delta \% \text { Tensilestrenght } \\
& E_{D I}=\Delta \% \text { density } / \Delta \% \text { Absorbed energy }
\end{aligned}
$$

\section{Results and Discussions}

\subsection{Fillers characterization}

Table 2 shows the compositions of samples and the amount of inorganic filler after the calcination test.

It is noticed a difference between the amount of filler theoretical and after the calcination test. This can be attributed to the low density and small dimensions of HGM, an amount of this filler is lost in the air during the feeding process. Also, some HGM can not pass through the die, getting held back in extruder ${ }^{[20]}$. The same could happen to the smallest glass fibers. However, there was a homogenous loss of fillers in all samples, around 5\% in weight for each one. Thus, this enables a fair comparison of mechanical properties between the samples, considering the same amount of reinforcement for all.

Figure 1a shows the SEM images to sample A, PA6 load with $30 \%$ of GF, after the calcination of the composite, and Figure $1 \mathrm{~b}$ shows the aspect ratio distribution of the glass fibers.

It was observed that glass fiber (GF) presents a smooth and uniform surface and average aspect ratio of $5.14 \pm 3.52 \mu \mathrm{m}$. There was a difficulty in determining the beginning and end of the fibers during the measurement, which justified the low $\mathrm{L} / \mathrm{D}$ value and high standard deviation. Nonetheless, fiber size reduction is expected due to the breakage during the extrusion at samples preparation. Lower aspect ratio results in worse mechanical properties, especially tensile strength and impact absorption ${ }^{[27,28]}$. Figure 2 a shows the SEM images to sample C, PA6 load with $25 \%$ of GF and $5 \%$ of HGM, after the calcination; through this analysis was possible to evaluate hollow glass microspheres, it has also a smooth surface and the average diameter was between 15 $\pm 5 \mu \mathrm{m}$. It's noticed a reduction in microspheres diameter due to the breakage during extrusion, owing to your thin brittle glass wall. The major reduction in diameter came to breakage of bigger HGM, which explains a $25 \%$ reduction on average diameter. Hu et al. ${ }^{[29]}$ studied the effect of broken HGM in silicon rubber and detected a enhance in mechanical

Table 2. Samples formulation with PA6, GF and HGM content relative and inorganic filler after calcination experiment.

\begin{tabular}{ccccc}
\hline Sample & $\begin{array}{c}\text { PA6 } \\
(\mathbf{w t} \%)\end{array}$ & $\begin{array}{c}\text { GF } \\
(\mathbf{w t} \%)\end{array}$ & $\begin{array}{c}\text { HGM } \\
\mathbf{( w t \% )}\end{array}$ & $\begin{array}{c}\text { Calcination } \\
(\mathbf{\%} \text { wt) }\end{array}$ \\
\hline A & 70.0 & 30.0 & 0.0 & $24.8 \pm 0.1$ \\
B & 70.0 & 27.0 & 3.0 & $25.3 \pm 0.1$ \\
C & 70.0 & 25.0 & 5.0 & $25.9 \pm 0.1$ \\
D & 70.0 & 22.5 & 7.5 & $25.1 \pm 0.2$ \\
E & 70.0 & 20.0 & 10.0 & $25.9 \pm 0.1$ \\
\hline
\end{tabular}



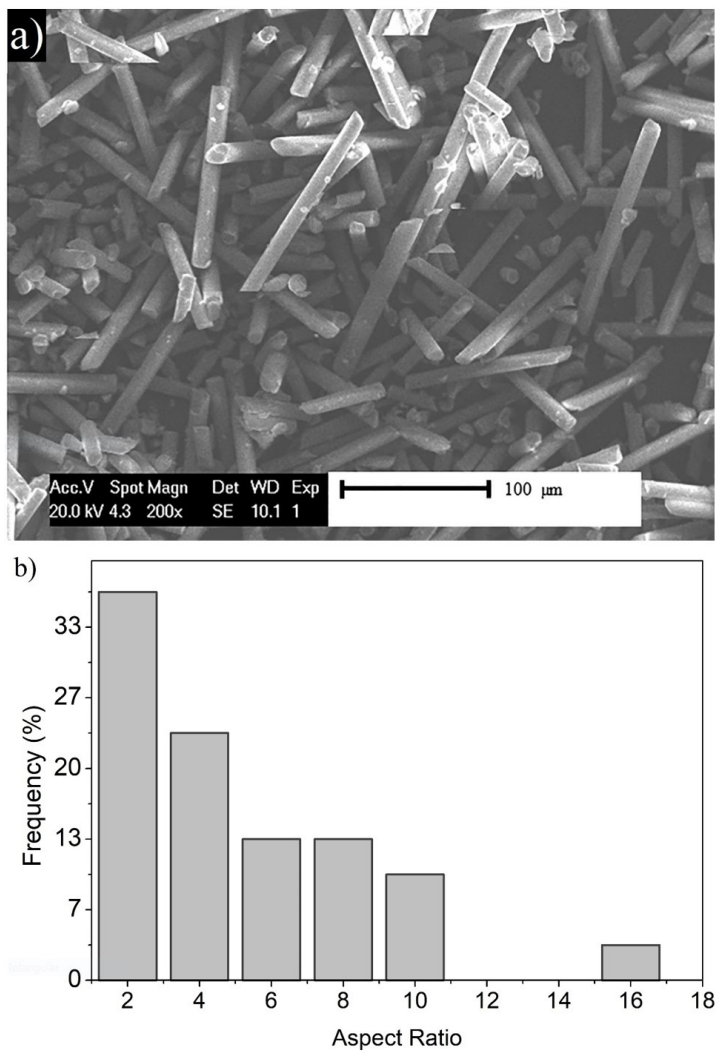

Figure 1. (a) SEM images of sample A after calcination process; (b) Aspect ratio distribution of sample A.

properties due to a bigger contact area between matrix and filler after the HGM break, this observation can explain the enhancement of mechanical properties described in this work in the next section. Fiber average aspect ratio is $5.38 \pm 2.19$ on sample $\mathrm{C}$. The difference in the glass fiber length between samples $\mathrm{A}$ and $\mathrm{C}$ is explained by the influence of HGM in attrition increase during extrusion ${ }^{[30]}$. Again, there was a difficulty in determining the beginning and end of the fibers, which justified the low $\mathrm{L} / \mathrm{D}$ value and high standard deviation.

A reduction in $\mathrm{L} / \mathrm{D}$ original value was expected due to attrition between flow matrix and fillers during extrusion ${ }^{[1,20]}$. Also, is well known that lower values of $\mathrm{L} / \mathrm{D}$ generate worst mechanical properties ${ }^{[28,30]}$. The average diameter of HGM was measured to analyze the breakage of microspheres during extrusion. A reduction in average diameter was noticed. Scientific papers describe an improvement in tensile and impact strength in composites with broken HGM due to a higher interfacial surface of the filler which leads to more chemical interactions. This improves the efficiency of strain mechanism of composites ${ }^{[2,31]}$.

\subsection{Composites characterization}

The micrographs of the surface of composites samples A, B, C, D and E, obtained by SEM, are showed in Figures 3-5.

By analyzing reference sample A, PA6 with $30 \%$ GF, Figure $3 \mathrm{a}$, it was observed that the glass fibers show uniform
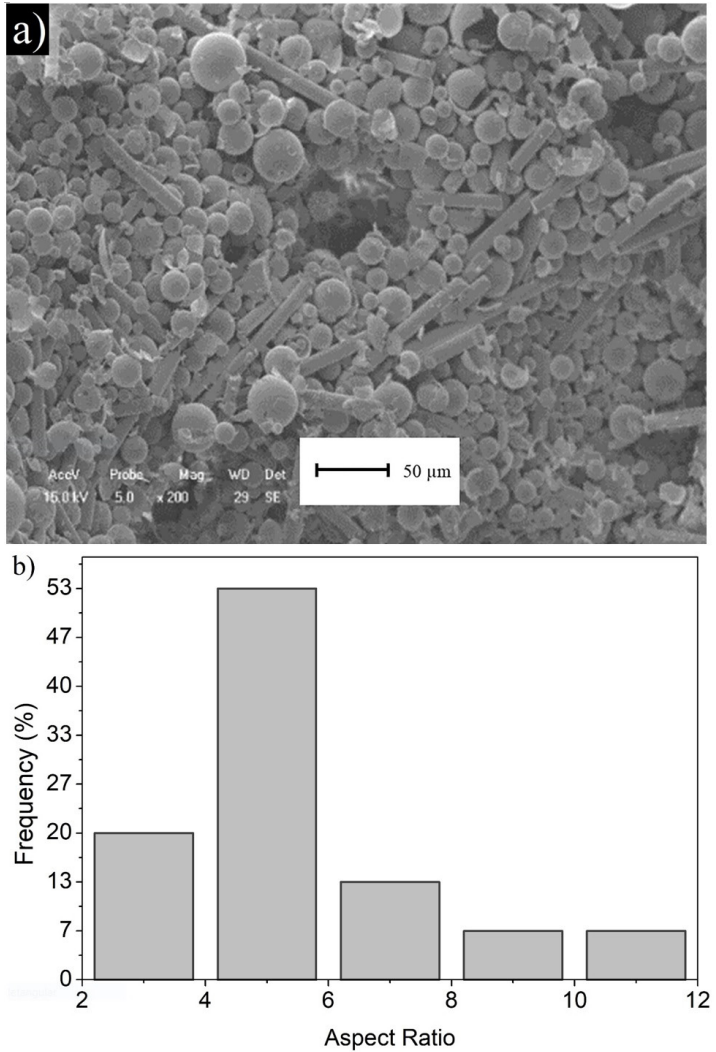

Figure 2. (a) SEM images of sample $\mathrm{C}$ after calcination process; (b) Aspect ratio distribution of glass fibers.

distribution through to the PA 6 matrix. However, some small holes were observed, probably resulting from the extraction of fibers during the cryogenic fracture (white circle). For sample B, PA6 with $27 \%$ GF and 3\% HGM, Figure 3b, it was a similar behavior was observed, that is, a uniform fillers distribution through to the PA6 matrix. Although the glass fibers are more adhered to the matrix than the HGM. This can be explained by the fact of GF was chemically treated with an organosilane, improving the interaction fiber-matrix. Due to the non-treated surfaces, HGM showed a weak interfacial adhesion with the matrix. Carvalho et al. ${ }^{[32]}$ studied the influence of interfacial interactions in a polypropylene (PP) /GF extruded composite reinforced with non-treated and aminosilane treated HGM. These authors had describe a difference in the interfacial interaction between matrix-HGM treated and matrix-HGM non-treated. With the treatment, the PP matrix wets almost all HGM, instead of the almost half of non-treated HGM. Kumar et al. ${ }^{[33]}$ concluded the same idea about the surface treatment on HGM after studying the morphology of PP reinforced with bamboo fiber and HGM. Again, SEM images showed the matrix all around the treated surface.

It can be noted that samples $\mathrm{C}, \mathrm{D}$ and $\mathrm{E}$, Figures 4 and 5 , despite having a larger amount of HGM than samples A and $\mathrm{B}$, do not show agglomerates and maintain good fillers distribution through to the PA6 matrix. These samples also presented holes due to cryogenic fracture. There are more 

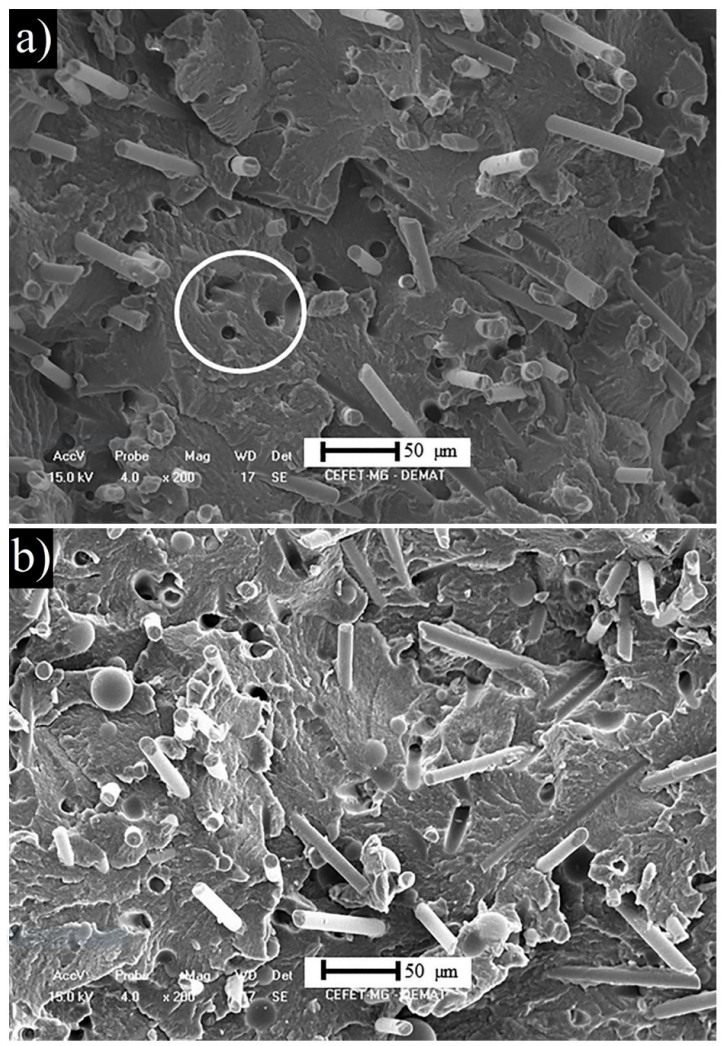

Figure 3. (a) SEM images of sample A after cryogenic fracture; (b) SEM images of sample B after cryogenic fracture $($ scale $=50 \mu \mathrm{m})$.

holes coming from the HGM pullout than from fibers. Also, can be noted that those holes have diameters similar to small HGM, about $6 \mu \mathrm{m}$. It was expected since a low ratio surface comes with a low adhesion surface between matrix and non-treated $\mathrm{HGM}^{[34,35]}$. Figure 6a show the adhesion failure in sample $\mathrm{D}(70 \% \mathrm{PA} 6 / 22,5 \% \mathrm{GF} / 7,5 \% \mathrm{HGM})$ with a zoom. It's possible to see an empty space around the filler.

On the other hand, as shown in Figure 6b, it can be seen that the PA6 matrix "wets" the glass fibers. Therefore, the fibers have a rough surface, unlike the smooth surface observed after the calcination test; the microspheres remain with the smooth surface. Such behavior can be justified by the presence of an organosilane compatibilizer on the glass fibers surface, which promotes improved chemical interaction between polymer and fiber. The microspheres, however, were not compatibilized. When matrix "wets" the fillers, chemical interactions improve mechanical properties. Although a poor adhesion between the phases leads to premature failure under mechanical stress. The empty space acts as a crack and propagates under loads ${ }^{[36,37]}$.

Samples density obtained according to the Archimedes principle, and the density reduction with the increase of the amount of HGM, in comparison to the PA6/GF with $30 \mathrm{wt} \%$ of filler are showed in Table 3.

The density test shows a great reduction in the in the density of the composites, in comparison to the reference sample, with the increasing fraction of hollow glass microspheres in the material. In Jang's study ${ }^{[10]}$, was used polycarbonate
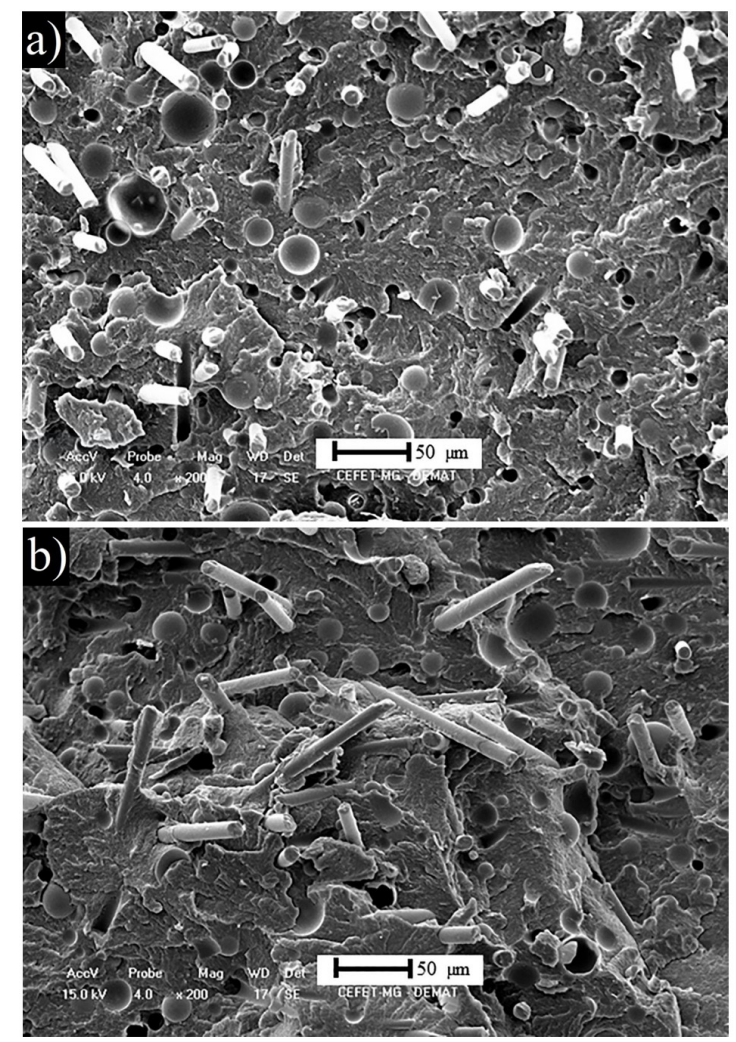

Figure 4. (a) SEM images of sample $C$ after cryogenic fracture $($ scale $=50 \mu \mathrm{m})$; (b) SEM images of sample D after cryogenic fracture $($ scale $=50 \mu \mathrm{m})$.

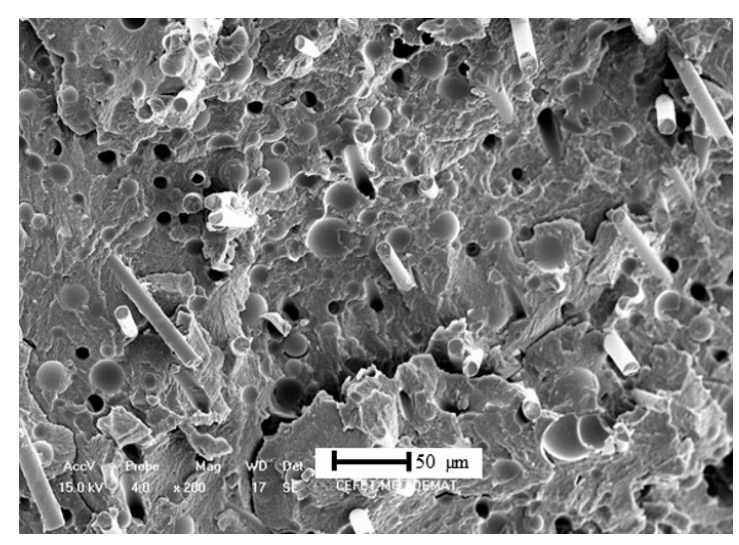

Figure 5. SEM images of sample E after cryogenic fracture (scale $=50 \mu \mathrm{m})$.

with density of $1.19 \mathrm{~g} / \mathrm{cm}^{3}$ and hollow glass microsphere $\left(\right.$ density $\left.=0.46 \mathrm{~g} / \mathrm{cm}^{3}\right) .15 \mathrm{wt} \%$ of filler granted a density reduction of $15.2 \%$ of the composite.

The mechanical properties, i.e. Young's modulus, tensile strength values, elongation at break, obtained by tensile strength test, and absorbed impact energy, obtained by Izod impact resistance test are shown in Figure 7.

The mechanical properties of hybrid composites were reduced with increase of amount of HGM in its composition, in comparison to the reference sample. All samples present the 


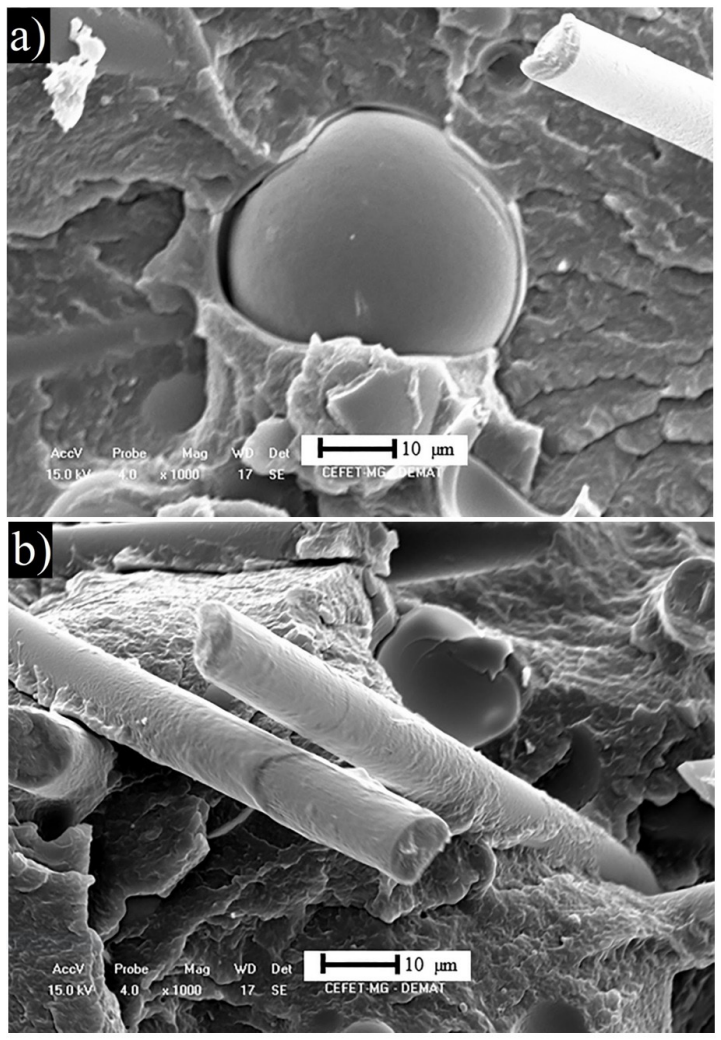

Figure 6. (a) SEM images of HGM after cryogenic fracture (scale $=10 \mu \mathrm{m}$ ); (b) SEM images of GF after cryogenic fracture (scale $=10 \mu \mathrm{m})$.

Table 3. Density test results and analyses of density reduction.

\begin{tabular}{ccc}
\hline Sample & Density $\left(\mathbf{g} / \mathbf{c m}^{3}\right)$ & $\begin{array}{c}\text { Density Reduction } \\
\mathbf{( \% )}\end{array}$ \\
\hline A & $1.32 \pm 0.004$ & - \\
B & $1.28 \pm 0.003$ & 3.0 \\
C & $1.22 \pm 0.009$ & 7.6 \\
D & $1.20 \pm 0.001$ & 9.1 \\
E & $1.12 \pm 0.024$ & 15.1 \\
\hline
\end{tabular}

same range of filler after the calcination experiment, so the mechanical properties could be evaluated using the selected mixing method. According to Figure 7, considering the high standard deviations, Young's modulus was the same to all samples, so it was supposed that hollow glass microspheres do not significantly affect this property. Tensile strength, elongation at break and impact resistance rate reduction of each formulation are summarized in Table 4. Negative values correspond to improvement on the property.

According to Table 4, there was a low reduction in the tensile strength, considering the lowest amount of glass fibers in sample $\mathrm{E}(70 \% \mathrm{PA} / 20 \% \mathrm{GF} / 10 \% \mathrm{HGM})$, remembering that glass fibers conferees better mechanical properties for these composites ${ }^{[6]}$. Also, a lower fiber aspect ratio is expected due to the increase of attrition during extrusion with high values of HGM in ternary composites ${ }^{[30]}$. Can be observed the same range of fiber aspect ratio between binary and ternary composites, so that should not be the reason for
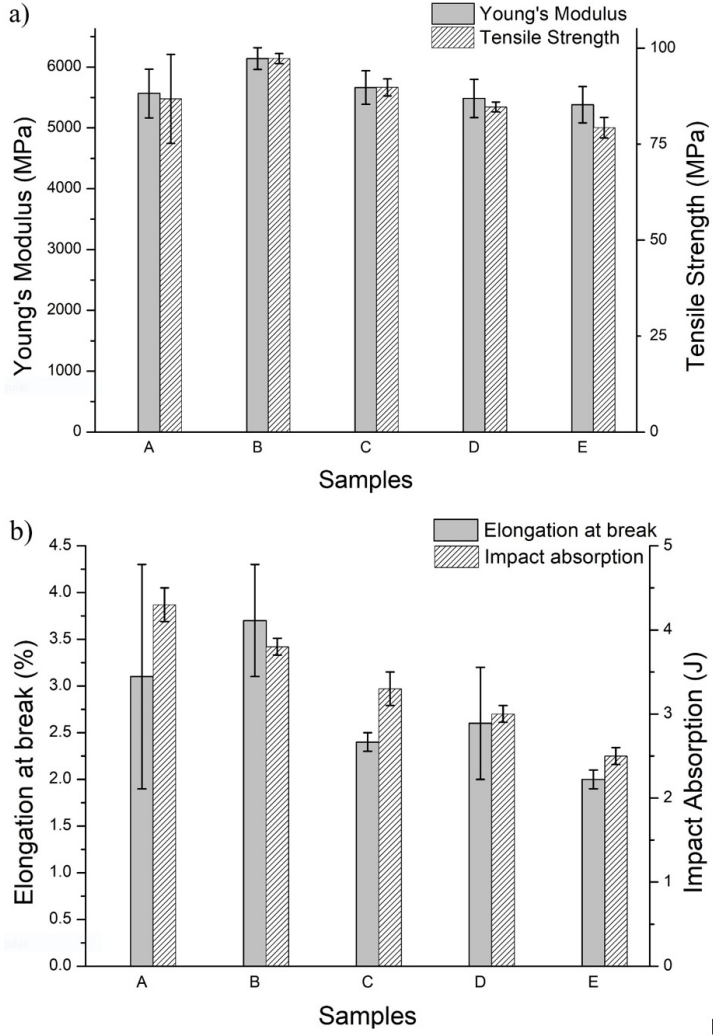

Figure 7. Mechanical properties of samples: (a) Young's modulus and tensile strength; (b) Elongation at break and impact absorption.

Table 4. Rate reduction of mechanical properties.

\begin{tabular}{cccc}
\hline Sample & $\begin{array}{c}\text { Tensile } \\
\text { Strength (\%) }\end{array}$ & $\begin{array}{c}\text { Elongation at } \\
\text { break (\%) }\end{array}$ & $\begin{array}{c}\text { Impact } \\
\text { Absorption } \\
(\%)\end{array}$ \\
\hline A & - & - & - \\
B & -12 & -19 & 12 \\
C & -3 & 23 & 23 \\
D & 2 & 16 & 30 \\
E & 9 & 35 & 42 \\
\hline
\end{tabular}

the improvement on mechanical properties. Nevertheless, sample B $(70 \% \mathrm{PA} / 27 \% \mathrm{GF} / 3 \% \mathrm{HGM})$ presented an improvement in properties compared to sample A. This result could be attributed to better distribution and/or dispersion of fillers in the thermoplastic matrix during processing ${ }^{[32]}$. Other reason that could explain the improvement is better physically interaction that small amount of HGM in ternary composites, like Hu detected in your study. Hu had reported the influence of broken HGM on silicon rubber, with and without intact spheres. Even the broken HGM can be a reinforcement on the composites if there is physical and/ or chemical interaction with the matrix, improved by the higher surface area, although it doesn't decrease the density. This can explain by broken HGM presenting a higher surface area than an intact microsphere. Doumbia' ${ }^{[31]}$ study corroborates with Hu's experiment. Doumbia studies the influence of the various types of hollow microspheres in high-impact 
PP matrix. As broken HGM presents a higher aspect ratio than an intact microsphere, and the only interaction between matrix and HGM is an $\mathrm{H}$ bond of hydroxyl group present on the surface of the filler, more surface ensures a higher probability of chemical interaction. Experimentally, it was observed a high elongation at break and high tensile strength compared with the theoretical value. Filler with good physical or chemical interaction with matrix and/ or another reinforcement increases the efficiency of strain mechanism. A small interparticle distance (GF and HGM) decreases substantially mechanical properties due to stress field superimpose ${ }^{[32]}$. The impact absorption had a relative reduction due to the non-adherence of some hollow glass microspheres with the matrix ${ }^{[38]}$. However, it could be improved if the hollow glass microsphere were compatibilized with an organosilane, avoiding those failures around the HGM.

In your study, Çelebi ${ }^{[39]}$ had compared mechanical properties of pure polypropylene, and the modification after add hollow glass microspheres and HGM silane-modified. The values of tensile strength were reduced, but when the filler is compatibilized, this reduction is smaller. Compared to pure PP, which presented $38 \mathrm{MPa}$ of tensile strength, samples with $10 \%$ and $20 \%$ untreated HGM presented 26 $\mathrm{MPa}$ (reduction of $32 \%$ ) and $21 \mathrm{MPa}$ (reduction of $45 \%$ ), respectively. Although, samples with $10 \%$ and $20 \%$ of silane modified HGM presented $28 \mathrm{MPa}$ (reduction of $26 \%$ ) and $23 \mathrm{MPa}$ (reduction of $39 \%$ ), a difference of $6 \%$ compared with value of pure PP. Elastic modulus was increased, at least $20 \%$, for compositions that had modified filler. The rate reduction of tensile strength from $\mathrm{PA} 6 / \mathrm{GF} / \mathrm{HGM}$ studied in this paper was smaller than the Çelebi's composites, due to affinity between the materials and fiber reinforcement. However, a treatment on the HGM surface can decrease this rate reduction on tensile strength.

To be sure which composition studied is most efficient, Table 5 presents a comparison with rate reduction between density and tensile strength $\left(\mathrm{E}_{\mathrm{DT}}\right)$, also density and energy absorption $\left(\mathrm{E}_{\mathrm{DI}}\right)$. Negative values indicate an increase in mechanical behavior.

In terms of absorbed energy, all samples present a near number of reduced density per reduced absorbed energy capacity. Now dealing with tensile strength, the most efficient sample is composition $\mathrm{D}$, once the aim of the study is mass reduction, but if it's a desire to improve mechanical proprieties and reduce mass, composition $\mathrm{C}$ is more efficient.

Analyzing the weight reduction of samples, Table 3 shows that a maximum reduction of $15 \%$ was achieved (sample E). In all composites studied, a good combination of weight reduction and mechanical properties maintenance was successfully obtained. For example, by replacing five percent of fibers glass with HGM in the composition, it was possible to reduce the composite density in almost $8 \%$, while the mechanical properties were practically the same observed in the reference sample.

However, after analyzing the results obtained, it's possible to have a composition of PA6, glass fiber and HGM that presents the same tensile resistance of PA/GF (70/30), but with a lower density. This composition should be between $5 \%$ and $7.5 \%$ of hollow glass microspheres.
Table 5. Comparative of ratio reduction of samples.

\begin{tabular}{ccc}
\hline Sample & EDT & EDI \\
\hline A & - & - \\
B & -0.25 & 0.26 \\
C & -2.19 & 0.33 \\
D & 3.76 & 0.30 \\
E & 1.75 & 0.36 \\
\hline
\end{tabular}

\section{Conclusions}

In this work, a composite of PA6 reinforced with glass fiber (GF) and Hollow glass microspheres (HGM) with light-weight and high-strength was successfully produced. Compared to the traditional PA6/GF (70/30) wt $\%$ composite, widely used today in automotive industries, the PA6/GF/HGM (70/22.5/7.5), and PA6/GF/HGM (70/25/5) formulations showed, respectively, a reduction of 9.1 and $7.6 \%$ in its density with a slight reduction in its mechanical properties. On the other hand, the PA6/GF/HGM (70/27/03) showed a reduction of $3 \%$ in the density and improvement properties compared to the reference sample, which was attributed to better distribution and/or dispersion of fillers in the thermoplastic matrix during processing, besides of the improvement made by broken HGM. The impact absorption reduction observed in the samples, with the increase of the amount of HGM in the composition was attributed to the non-adherence of some hollow glass microspheres in the PA matrix, evidenced in the SEM analysis. However, it could be improved if the hollow glass microsphere were compatibilized with an organosilane, avoiding those failures around the HGM. Thus, was concluded that composites can be used to replace some automotive components, which are currently made by the composite PA6/GF (70/30) wt $\%$ composite, providing a considerable weight reduction for these materials.

\section{Acknowledgements}

The authors thank LANXESS for the PA6 supply and the aid with the composite processing.

\section{References}

1. Plocher, J., \& Panesar, A. (2019). Review on design and structural optimisation in additive manufacturing: towards next-generation lightweight structures. Materials \& Design, 183, 108164. http://dx.doi.org/10.1016/j.matdes.2019.108164.

2. Akampumuza, O., Wambua, P. M., Ahmed, A., Li, W., \& Qin, X.-H. (2016). Review of the applications of biocomposites in the automotive industry. Polymer Composites, 38(11), 25532569. http://dx.doi.org/10.1002/pc.23847.

3. Vyncke, G., Fiorio, R., Cardon, L., \& Ragaert, K. (2020). The effect of polyethylene on the properties of talc-filled recycled polypropylene. Plastics, Rubber and Composites, 1-8. http:// dx.doi.org/10.1080/14658011.2020.1807729.

4. Awan, M. O., Shakoor, A., Rehan, M. S., \& Gill, Y. Q. (2021). Development of HDPE composites with improved mechanical properties using calcium carbonate and NanoClay. Physica $B$, Condensed Matter, 606, 412568. http://dx.doi.org/10.1016/j. physb.2020.412568.

5. Ohayon-Lavi, A., Buzaglo, M., Ligati, S., Peretz-Damari, S., Shachar, G., Pinsk, N., Riskin, M., Schatzberg, Y., Genish, I., \& 
Regev, O. (2020). Compression-enhanced thermal conductivity of carbon loaded polymer composites. Carbon, 163, 333-340. http://dx.doi.org/10.1016/j.carbon.2020.03.026.

6. Aseer, J. R., Deka, K., Kumar, S., Muralidharan, S., \& Sharma, A. (2016). Effect of fiber content on mechanical properties of Glass Fiber Reinforced Polymer (GFRP) composites. Journal of Material Science and Mechanical Engineering, 3(3), 239-242. Retrieved in 2021, August 13, from https://krishisanskriti.org/ vol_image/10Jun201609063744\%20\%20\%20\%20\%20\%20 J\%20\%20Ronald $\% 20$ Aseer $\% 20 \% 20 \% 20 \% 20 \% 20 \% 20 \% 20$ $\% 20 \% 20 \% 20 \% 20239-242 \% 20 \% 20 \% 20 \% 20 \% 20 \% 20 \% 20$ $\% 201 . p d f$

7. Anandakumar, P., Timmaraju, M. V., \& Velmurugan, R. (2021). Development of efficient short/continuous fiber thermoplastic composite automobile suspension upper control arm. Materials Today: Proceedings, 39(Pt 4), 1187-1191. http://dx.doi. org/10.1016/j.matpr.2020.03.543.

8. Papageorgiou, D. G., Kinloch, I. A., \& Young, R. J. (2016). Hybrid multifunctional graphene/glass-fibre polypropylene composites. Composites Science and Technology, 137, 44-51. http://dx.doi.org/10.1016/j.compscitech.2016.10.018.

9. Ravishankar, B., Nayak, S. K., \& Kader, M. A. (2019). Hybrid composites for automotive applications - A review. Journal of Reinforced Plastics and Composites, 38(18), 835-845. http:// dx.doi.org/10.1177/0731684419849708.

10. Jang, K.-S. (2020). Low-density polycarbonate composites with robust hollow glass microspheres by tailorable processing variables. Polymer Testing, 84, 106408. http://dx.doi.org/10.1016/j. polymertesting.2020.106408.

11. Ding, J., Liu, Q., Zhang, B., Ye, F., \& Gao, Y. (2020). Preparation and characterization of hollow glass microsphere ceramics and silica aerogel/hollow glass microsphere ceramics having low density and low thermal conductivity. Journal of Alloys and Compounds, 831, 154737. http://dx.doi.org/10.1016/j. jallcom.2020.154737.

12. Jiao, C., Wang, H., Li, S., \& Chen, X. (2017). Fire hazard reduction of hollow glass microspheres in thermoplastic polyurethane composites. Journal of Hazardous Materials, 332, 176-184. http://dx.doi.org/10.1016/j.jhazmat.2017.02.019. PMid:28324711.

13. Liang, J. Z., \& Li, F. H. (2006). Measurement of thermal conductivity of hollow glass-bead-filled polypropylene composites. Polymer Testing, 25(4), 527-531. http://dx.doi. org/10.1016/j.polymertesting.2006.02.007.

14. Zhang, Z., Jiang, H., Li, R., Gao, S., Wang, Q., Wang, G., Ouyang, X., \& Wei, H. (2020). High-damping polyurethane/ hollow glass microspheres sound insulation materials: preparation and characterization. Journal of Applied Polymer Science, 138(10), 49970. http://dx.doi.org/10.1002/app.49970.

15. Awais, H., Nawab, Y., Anjang, A., Akil, H. M., \& Abidin, M. S. Z. (2020). Mechanical properties of continuous natural fibres (Jute, Hemp, Flax) reinforced polypropylene composites modified with hollow glass microspheres. Fibers and Polymers, 21(9), 2076-2083. http://dx.doi.org/10.1007/s12221-020-2260-z.

16. Borges, T. E., Almeida, J. H. S., Jr., Amico, S. C., \& Amado, F. D. R. (2016). Hollow glass microspheres/piassava fiberreinforced homo- and co-polypropylene composites: preparation and properties. Polymer Bulletin, 74(6), 1979-1993. http:// dx.doi.org/10.1007/s00289-016-1819-8.

17. Bourry, D., \& Favis, B. D. (1998). Morphology development in a polyethylene/polystyrene binary blend during twinscrew extrusion. Polymer, 39(10), 1851-1856. http://dx.doi. org/10.1016/S0032-3861(97)00397-2.

18. Pandey, V., Chen, H., Ma, J., \& Maia, J. M. (2021). Extensiondominated improved dispersive mixing in single-screw extrusion. Part 2: comparative analysis with twin-screw extruder. Journal of Applied Polymer Science, 138(5), 49765. http://dx.doi. org/10.1002/app.49765.

19. Wilson, G. F., \& Eckstein, Y. (1991). US Patent No. 5017629 A. Akron, Ohio: The BF Goodrich Company. Retrieved in 2021, August 13, from https://patents.google.com/patent/US5017629A/ en?oq $=+5 \% 2 \mathrm{c} 017 \% 2 \mathrm{c} 629$

20. Shira, S., \& Buller, C. (2015). Mixing and dispersion of hollow glass microsphere products. In: Amos, S. E., \& Yalcin, B., editors. Hollow glass microspheres for plastics, elastomers, and adhesives compounds (pp. 241-271). USA: Elsevier Inc. http://dx.doi.org/10.1016/B978-1-4557-7443-2.00011-6.

21. Kim, S., Wu, H., Devega, A., Sico, M., Fahy, W., Misasi, J., Dickens, T., \& Koo, J. H. (2020). Development of polyetherimide composites for use as $3 \mathrm{D}$ printed thermal protection material. Journal of Materials Science, 55(22), 9396-9413. http://dx.doi. org/10.1007/s10853-020-04676-6.

22. Özbay, B., \& Serhatl, E. (2020). Processing and characterization of hollow glass-filled polyamide 12 composites by selective laser sintering method. Materials Technology, 1-11. http:// dx.doi.org/10.1080/10667857.2020.1824149.

23. Ksouri, I., De Almeida, O., \& Haddar, N. (2017). Long term ageing of polyamide 6 and polyamide 6 reinforced with $30 \%$ of glass fibers: physicochemical, mechanical and morphological characterization. Journal of Polymer Research, 24(8), 133. http://dx.doi.org/10.1007/s10965-017-1292-6.

24. Caputo, F., Lamanna, G., De Luca, A., \& Armentani, E. (2020). Thermo-mechanical investigation on an automotive engine encapsulation system made of fiberglass reinforced polyamide PA6 GF30 material. Macromolecular Symposia, 389(1), 1900100. http://dx.doi.org/10.1002/masy.201900100.

25. Berman, A., DiLoreto, E., Moon, R. J., \& Kalaitzidou, K. (2020). Hollow glass spheres in sheet molding compound composites: limitations and potential. Polymer Composites, 42(3), 1279-1291. http://dx.doi.org/10.1002/pc.25900.

26. Lai, C.-C., Chen, S.-Y., Chen, M.-H., Chen, H.-L., Hsiao, H.-T., Liu, L.-C., \& Chen, C.-M. (2019). Preparation and characterization of heterocyclic polyamide 6 (PA 6) with high transparencies and low hygroscopicities. Journal of Molecular Structure, 1175, 836-843. http://dx.doi.org/10.1016/j. molstruc.2018.08.032.

27. Yoo, D.-Y., Kim, S., Park, G.-J., Park, J.-J., \& Kim, S.-W. (2017). Effects of fiber shape, aspect ratio, and volume fraction on flexural behavior of ultra-high-performance fiber-reinforced cement composites. Composite Structures, 174, 375-388. http:// dx.doi.org/10.1016/j.compstruct.2017.04.069.

28. Yazici, S., Inan, G., \& Tabak, V. (2007). Effect of aspect ratio and volume fraction of steel fiber on the mechanical properties of SFRC. Construction \& Building Materials, 21(6), 1250-1253. http://dx.doi.org/10.1016/j.conbuildmat.2006.05.025.

29. Hu, Y., Mei, R., An, Z., \& Zhang, J. (2013). Silicon rubber/ hollow glass microsphere composites: influence of broken hollow glass microsphere on mechanical and thermal insulation property. Composites Science and Technology, 79, 64-69. http:// dx.doi.org/10.1016/j.compscitech.2013.02.015.

30. Yoo, Y., Spencer, M. W., \& Paul, D. R. (2011). Morphology and mechanical properties of glass fiber reinforced Nylon 6 nanocomposites. Polymer, 52(1), 180-190. http://dx.doi. org/10.1016/j.polymer.2010.10.059.

31. Doumbia, A. S., Bourmaud, A., Jouannet, D., Falher, T., Orange, F., Retoux, R., Le Pluart, L., \& Cauret, L. (2015). Hollow microspheres - poly-(propylene) blends: relationship between microspheres degradation and composite properties. Polymer Degradation \& Stability, 114, 146-153. http://dx.doi. org/10.1016/j.polymdegradstab.2014.12.024.

32. Carvalho, G. B., Canevarolo, S. V., \& Sousa, J. A. (2020). Influence of interfacial interactions on the mechanical behavior 
of hybrid composites of polypropylene / short glass fibers / hollow glass beads. Polymer Testing, 85, 106418. http://dx.doi. org/10.1016/j.polymertesting.2020.106418.

33. Kumar, N., Mireja, S., Khandelwal, V., Arun, B., \& Manik, G. (2016). Light-weight high-strength hollow glass microspheres and bamboo fiber based hybrid polypropylene composite: a strength analysis and morphological study. Composites. Part B, Engineering, 109, 277-285. http://dx.doi.org/10.1016/j. compositesb.2016.10.052.

34. Bauer, P., Becker, Y. N., Motsch-Eichmann, N., Mehl, K., Müller, I., \& Hausmann, J. (2020). Hybrid thermoset-thermoplastic structures: an experimental investigation on the interface strength of continuous fiber-reinforced epoxy and short-fiber reinforced polyamide 6. Composites Part C: Open Access, 3, 100060. http://dx.doi.org/10.1016/j.jcomc.2020.100060.

35. Liang, J.-Z. (2013). Reinforcement and quantitative description of inorganic particulate-filled polymer composites. Composites. Part B, Engineering, 51, 224-232. http://dx.doi.org/10.1016/j. compositesb.2013.03.019.

36. Zhang, D., Guo, J., \& Zhang, K. (2015). Effects of compatilizers on mechanical and dynamic mechanical properties of polypropylene-long glass fiber composites. Journal of Thermoplastic Composite Materials, 28(5), 643-655. http:// dx.doi.org/10.1177/0892705713486141.

37. Haverroth, G. E., \& Soares, B. G. (2021). Polypropylene and hollow glass microspheres compatibilization via addition of compatibilizing agents. Polymer Composites, 42(9), 4872-4883. http://dx.doi.org/10.1002/pc.26196.

38. Sung, G., \& Kim, J. H. (2017). Influence of filler surface characteristics on morphological, physical, acoustic properties of polyurethane composite foams filled with inorganic fillers. Composites Science and Technology, 146, 147-154. http:// dx.doi.org/10.1016/j.compscitech.2017.04.029.

39. Çelebi, H. (2017). Thermal conductivity and tensile properties of hollow glass microsphere/polypropylene composites. Anadolu University Journal of Science and Technology A Applied Sciences and Engineering, 18(3), 746-753. http:// dx.doi.org/10.18038/aubtda.323483.

Received: Aug. 13, 2021

Revised: Dec. 03, 2021

Accepted: Dec. 06, 2021 